\title{
Trends and Challenges of Sustainable Energy and Water Research in North Africa: Sahara Solar Breeder Concerns at the Intersection of Energy/Water
}

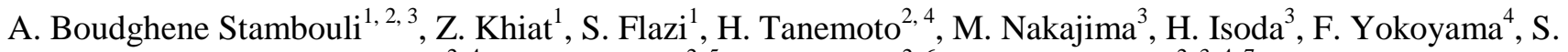 \\ Hannachi $^{2,4}$, K. Kurokawa ${ }^{2,5}$, M. Shimizu ${ }^{2,6}$ and H. Koinuma ${ }^{2,3,4,7}$ \\ ${ }^{1}$ University of Science and Technology of Oran, USTO-MB, Algeria \\ BP 1505, EL M'Naouer, Oran (31000). Algeria. \\ Tel \& Fax: 00213415603 29/01. E-mail: stambouli@ssb-foundation.com \\ ${ }^{2}$ Sahara Soar Breeder Foundation (SSBF), http://www.ssb-foundation.com/ \\ ${ }^{3}$ ARENA (Alliance for Research for North Africa), Tsukuba University, Japan \\ ${ }^{4}$ Nippon Pure Water Co. Ltd. Japan \\ ${ }^{5}$ Tokyo Institute of Technology, Japan \\ ${ }^{6}$ Seavac Corp. Ltd. Japan \\ ${ }^{7}$ Graduate School of Frontier Science, University of Tokyo, Japan
}

\begin{abstract}
In this contribution a particular attention is being given to the strategic objective for the establishment of a North Africa (NA) countries cooperation on water and clean energy superhighway as the solution to regional energy challenges, water shortages, climate change and other environmental problems arising from the current fossil-fuel heavy global energy paradigm. Advanced and technical know-how and resources of Japan, through the Sahara Solar Breeder (SSB) project, can facilitate to achieve sustainable development in the region, cooperation to accelerate and expand its research activity with ambitious quantitative targets for solutions between the growing water crisis in NA and energy resources (fossil and renewables energies (RE)). With global energy demand set to rise significantly over the next 15 years, there will be a pressing need for fresh investment in new output capacity across the entire water/energy supply chain. It is still believed and emphasized that Photovoltaic (PV) will be a significant contributor within a portfolio of energy sources in the coming 10 to 20 years and that SSB is providing science and technology that are poised to play a transformative role in providing clean and sustainable water/energy for the whole world. Japan's energy/water innovative strategy for NA is encouraging since problems cannot be solved by one country alone hence local, regional and global cooperation is crucial.
\end{abstract}

\section{Key words}

Energy, Water, SSB, Renewable Energy and Water, Japan, Sustainability

\section{Introduction}

As we approach a 2050 (10 billion persons on earth), physical and environmental constraints in our use of water and energy resources are beginning to manifest themselves. Water and energy resources, intricately connected and increasingly scarce, are integral parts of the heritage of humanity. They require us to implement policies and strategies adapted to sustainable development in that:
- Energy security, Economic growth and Environmental protection are the national energy policy drivers of any country of the world;

- Energy is central to achieving the interrelated economic, social, and environmental aims of sustainable human development;

- Water is a fundamental part of our lives. It's a free and renewable natural resource. Human survival is dependent on water which has been ranked by experts as second only to oxygen as essential for life;

- Energy and water resources are intricately connected: we use energy to help us treat, clean and transport the water we need, and we use water to help us produce the energy we need.

According to the estimation done by the International Energy Agency (IEA), a 53\% increase in global energy consumption is foreseen by 2030 , energy security is becoming a serious issue as fossil fuels are non-RE and will deplete eventually in near future. In addition, the world's oil resources will peak within a few decades to come ( 80 years at the most), and in the search for other sustainable alternatives to mitigate some political, economic and environmental issues currently associated with the heavy reliance on fossil fuel, it is inevitable that the world is heading towards RE and new energy economy, to reach sustainability, by promoting clean energy technologies, pursuing energy efficiency and developing RE forms which are three orders of magnitude larger than current global energy use [1]. Climate changes, manifested in various forms, threaten the fragile balance of our ecosystem and require us to implement policies and strategies adapted to sustainable development.

For this reason, NA countries seek technologies from all disciplines applicable in RE, energy efficiency (EE) and water. Indeed, considering them together, by improving access to clean water and green modern energy, offers substantial economic and environmental benefits for the 
region as well as a unique opportunity of technological advancing in the energy and water fields. The idea of valorisation of water and energy resources for innovation in NA is to give a vision about the future, take into account the experience of the water and energy sectors during the last decade, about the development of the RE, focused from a double perspective: regulative and technological. While the NA region has shortage in water resources, it is blessed with overwhelming distributed RE sources in that solar energy is called to be one of the most relevant players in the basket of the future as seen in figure 1. Energy of sun shine in NA, also known as the Sunbelt, is huge, $0.01 \%$ utilization would cover the entire world.

MENA population is young and growing rapidly. With an average growth rate of $2.1 \%$ per year, MENA Region has one of the world's most rapidly expanding populations. Population Growth Projection is around 160\% [2,3]. This offers a unique opportunity of technological advancing in the water/energy field. Indeed, improved access to clean water and green modern energy in the region is a fundamental step to poverty reduction with advanced and technical know-how and resources of the industrialized nations, such as Japan, can facilitate to achieve sustainable development in the region.

\section{Water and energy linkage}

Water and energy uses are closely linked in that energy production uses and pollutes water and water use requires significant energy (globally, commercial energy consumed for delivering water, such as lifting ground water, desalinating, threating and pumping water through pipes, is about $7 \%$ of total world consumption) [4]. Limits to each are beginning to affect the other; yet energy and water issues are rarely integrated in policy. Energy and water policy can also be expressed in similar terms. The first priority of energy policy should be the wise, efficient use of whatever energy supplies are available. The same is true of water - priority should be given to the wise, efficient use of whatever water supplies exist. By considering water and energy together will offer substantial economic and environmental benefits for the NA region. In addition, the realities of climate change affects policies in both areas. It is after focusing on efficient use of existing resources that attention must be focused on new energy and water supplies that meet sustainability and environmental requirements. We therefore need to achieve the following objective:

- Establish strong links with the political process that lead to recommendations which will advise governments on the best approach to the links between water and energy;

- Establish common understanding and cooperation between actors from the water and energy sectors;

- Establish a network of policy makers in charge of water and energy involving developed countries and developing countries of NA to enhance levels of dialogue and awareness on all aspects link water lenergy;
- Initiate a major new research program that will address the connection between water /energy availability and economic sustainability.

We have much to contribute all, as a social responsibility duty, to achieve water and energy security, the linkage between the two must be recognized and acted upon. Without access to both, economic growth and job creation cannot take place and poverty cannot be averted. Figure 4 shows how we need science and technology that are poised to play a transformative role in providing clean and sustainable water and energy. SSB project may be a solution!

\subsection{Various forms of energy}

Energy is the engine of the universe, engine of all the fundamental processes of the nature on earth and engine of the world economy. The world is full of energy resources but their supply is finite. It also needs to be converted into power in order to make use of it. Our response is to find ways to use these resources more efficiently and develop new sources for energy. The different forms of energy are summarized as being fossil, fissile, renewable and new energies which can be presented as: Mechanical, Chemical, Electrical, Nuclear and Thermal energies. Energy researchers should creatively apply their knowledge of science (physics, math and chemistry), engineering (electrical and mechanical) and economics to confront the global challenges of energy supply and demand [5] (figure 2).

\subsubsection{Energy and sustainability}

To understand the implications for energy supply, table 2 presents a brief review of the energy linkage with other sustainable development issues such as water, health, biodiversity and agriculture. Energy availability can, therefore, severely constrains the four critical elements of sustainable development, a major goal of NA countries policy. Population growth and economic development are driving a steadily increasing demand for new energy supplies, and global demand for energy has more than tripled over the past half century. The future demand for electricity, assessed from time to time by the IEA, shows that the world's electricity consumption is expected almost to double by the year 2020 [6].

Table 1 shows clean energy, expressed as a percentage of total energy use in NA's countries. Clean energy is noncarbohydrate energy that does not produce carbon dioxide when generated. It includes hydropower, geothermal, wind and solar power, among others. Note that the Arab world presents a percentage of total energy of about 0.39 . Table 1 also shows the values of energy intensity in 2050 . Energy intensity is a measure of the energy efficiency of a nation's economy. It is calculated as units of energy per unit of GDP (high energy intensities indicate a high price or cost of converting energy into GDP and low energy intensity indicates a lower price or cost of converting energy into GDP). 


\subsection{Various forms of water}

An important feature of the earth's supply of fresh water is its non-uniform distribution around the globe. Water, for which there are no substitutes, has always been mankind's most precious resource. The struggle to control water resources has shaped human political and economic history, and water has been a source of tension wherever water resources are shared by neighbouring peoples. Globally, there are 215 international rivers and 300 ground water basins and aquifers shared by two or more countries [7].

There may be renewable and non-renewable sources of water in that:

- Non-renewable resources are stock limited with no effective recharge;

- Renewable resources are flow limited;

- Water and energy exhibit characteristics of both: but while most of our water use is renewable, most energy use is non-renewable.

Renewable water is continuously renewed within reasonable time spans by the hydrological cycle, such as that in streams, reservoirs, or aquifers that refill from precipitation, runoff, or groundwater recharge.

We'll never run out of water overall, it is (mostly) renewable. We will run up against renewable flow limits that are a combination of natural and economic constraints. Where water is non-renewable we will run into stock constraints. We are increasingly hitting (or exceeding) peak ecological water limits. Hitting these limits has social, economic, and political implications (figure 3) [8].

\subsubsection{Water and sustainability}

The water linkage with some important aspects of lives, such as education, health, poverty and hunger, is depicted in table 2. The importance of access to clean water cannot be overstated. Poor health, hunger and a lack of education are symptoms of the true problems: No clean water. Together they lead to a cycle of poverty.

The column 1 of table 3 shows the total renewable water resources in NA's countries. It corresponds to the maximum theoretical yearly amount of water actually available for the country at a given moment. Note that the current world total renewable water resources: $~ 53719$ $\mathrm{km}^{3}$ / year. Total renewable water resources provides the water total available to a country but does not include water resource totals that have been reserved for upstream or downstream countries through international agreements. Note that these values are averages and do not accurately reflect the total available in any given year. Annual available resources can vary greatly due to shortterm and long-term climatic and weather variations.

The column 2 of table 3 shows total renewable water resources per capita by country. Note that the current world total renewable water resources: $\sim 24,776 \mathrm{~m}^{3}$ /inhabitant/year (24,776,000 litres for each person).

The column 3 of table 3 shows the per cent of total renewable water resources dependency ratio or originating outside the country. Dependency ratio may theoretically vary between $0 \%$ and $100 \%$. A country with a dependency ratio equal to $0 \%$ does not receive any water from neighbouring countries. A country with a dependency ratio equal to $100 \%$ receives all its renewable water from upstream countries, without producing any of its own. This indicator does not consider the possible allocation of water to downstream countries.

The column 4 of table 3 shows surface water and ground water withdrawal as percentage of total renewable water resources. Water withdrawal is the quantity of water removed from available sources for human use (in the agricultural, domestic and industrial sectors), expressed as a percentage of the total volume of water available annually through the hydrological cycle (total actual renewable water resources). The terms water resources and water withdrawal are understood as freshwater resources and freshwater withdrawal.

[Freshwater withdrawal as \% of total renewable water resources $($ actual $)]=100 *$ [Total freshwater withdrawal (surface water + groundwater)] / [Water resources: total renewable (actual)]

The column 5 of table 3 shows total water withdrawal per capita by country. Water withdrawal is the quantity of water removed from available sources for use in any purpose. Water drawn-off is not necessarily entirely consumed and some portion may be returned for further use downstream.

\section{Energy research themes for NA}

In their plans to move beyond heavy dependence on fossil fuel imports (Morocco and Tunisia) or to maximize export revenues from domestic oil and gas reserves (Libya, Algeria and Egypt), the NA countries stand at a crossroads in terms of energy policy: interest in adopting RE and/or nuclear energy presents opportunities for a strategic realignment of national development paths. Placed in the global Sunbelt, rich in wind, geothermal and hydropower resources, the NA countries boast abundant potential for RE production. Although a series of clean energy policy initiatives have recently been introduced in the region, RE resources largely remain untapped. Current efforts to establish large-scale solar power exports to the European Union (EU) - including the Mediterranean Solar Plan, the Desertec and the SSB project - anticipate a substantial uptake of RE in NA [9]. In this section, we try to provide a platform to analyse recent trends in the NA energy systems research, as well as their implications for wider energy governance, in the context of this current crossroads for strategic energy investment and development.

\subsection{Energy training and technology transfer, main categories}

Current trends and prospects for RE in NA, covering optimization of market and technological options, regional energy infrastructure challenges (e.g. in terms of generation capacity, energy security and integration with European energy and carbon markets) and politicaleconomic governance contexts are analysed. There are also in-depth insights on clean energy policy development in NA. Training and technology transfer, main categories, on energy, can be summarized as follows: 
- Technologies that are currently applicable for worldwide cost-effective application (energy efficient buildings, off-grid PV, commercial solar water heating);

- Technologies in need of minor development (CSP stations, wind energy);

- Energy science-based approach towards developing smart solutions;

- Appropriate strategies to provide training for the optimization and management of energy use that contributes to a prosperous environment (climatefriendly energy supply);

- Provide NA partners with access to the, for example, Japan's Universities advanced energy and sustainability research topics. The two sides communicate their research information and findings for procession and dissemination in the framework of the SSB project for example;

- As for EE, technologies are sought that can be deployed within NA's operations or more broadly in the MENA region to reduce energy consumption, carbon emissions, and reduce the rapid growth in domestic demand (air conditioning and cooling during summertime). There are many other opportunities for efficiency improvements including building and construction materials, waste heat recovery systems, lighting, etc.

- Sharing best practice examples to relevant energy sector (share projects aiming at improving social and community services, at management of natural resources and at creating income-generating activities);

- Unlocking climate finance: evaluating the current financial situation to determine how much more is required to reach current $\mathrm{RE}$ generation targets;

- Find how can solar energy act as a creator of sustainable jobs in NA?

\subsection{Energy innovative research for $N A$}

In this section, we briefly set out some proposed innovative researches areas for the interest of NA countries in alternative energy futures. These are proposed below:

- In sunny NA, solar energy is the energy source of today and tomorrow. And, from the west to the east of the region, wind energy can be used. Both alternative energy sources will play a key role in the SSB and Desertec projects;

- New technologies with a view to long term energy sustainability;

- $\quad$ NA has lots of open land, and lots of sand which is rich in silicon; which is needed to make poly-silicon for the solar industry (joint venture with the Sahara Solar Breeder project team). With this move, NA, with the help of Japan, can slowly begin to make some moves diversifying out of oil, which is its only real exportable commodity - and towards solar power and sand-based poly-silicon, the commodities that it is truly rich in. And since NA is expected to be among the major PV growth regions during next years, it will be considered as a smart move;

- Establish a conceptual and analytical framework for the assessment and monitoring of energy impacts on the environment;

- Since NA has abundant solar energy resources suitable for both concentrating and non-concentrating systems. We seek innovative research in solar technologies; particularly those tackling unique challenges to solar systems in the region such as extreme ambient temperatures, dust, sand, humidity...;

- identifying research challenges and trends in solar power generation;

- NA seeks to be involved in the breakthrough technologies which are applicable in NA's operations, or more generally of strategic importance to the region.

\section{Water research themes for NA}

Countries in NA region face problems of water shortage due to the semi-arid climate and an increasing demand created by population and economic growth. The water situation in NA region is precarious. Population and development have overwhelmed traditional management practice. It is projected that the per capita renewable water supply will fall from 3,430 cubic meters in 1960, to 667 cubic meters in 2025. In several countries of the region, renewable freshwater will barely cover basic human needs within two decades. Development of water resources has been impeded by various reasons including the lack of technology and public awareness.

With the political movement in NA under way (Tunisia, Libya and Egypt), water issues have to take the centre stage. Co-operative water resources development should immediately follow to maintain a sustainable growth and prosperity. In view of the impending needs, a regional water resources consortium should be formed to provide training and technical assistance, to promote information and technology exchange, to provide expertise for arbitrating water conflicts (if happened), to organize long term and regional planning, and to serve as a centre of excellence for relevant technologies in the region using information technology support [10,11]. Managing water resources and preserving water quality require regional and international efforts.

\subsection{Water training and technology transfer, main categories}

Technology provides opportunities for helping resolve some of these problems. Information on existing technology and science can be a basis for creating cooperative actions amongst countries in the region. Training and technology transfer, main categories, on water, can be summarized as follows:

- The availability of potable water is one of the most pressing issues in the world, particularly in the 
MENA region where water production is a costly and energy-intensive process. With the NA's growing economy and rising population, it is crucial to identify a sustainable desalination solution to meet the long-term water needs;

- NA countries should launch renewably-powered desalination projects, existing desalination technology will of course continue to play its role in providing safe water. The water concerned research will have to explore ways to harness natural resources, like solar and wind. The overall goal is to have a utility scale desalination plants that will be powered by either solar, wind or even a combination of the two or several other technologies if necessary;

- Connecting desalination technologies to renewable energy enables the NA countries to capitalize on their abundant resources, such as solar, as a solution to improve water security. New, less energy-intensive water cleansing techniques could revolutionize NA's desalination industry, free up important energy exports and provide residents a greater sense of water security;

- Research in technologies applicable across the water value chain including, distribution, end-use, water and wastewater treatment, and recycling;

- Develop appropriate strategies and provide training, design documents and counselling services for the proper optimization and an integrated management of water use that contributes to a prosperous environment.

\subsection{Water innovative research for $N A$}

The objectives of innovative research for NA are to initiate a scientific body aiming to organize efforts on water resources, quality, and economical issues in the region. This will also serve as a consulting arm for governments in the region initiating national or international water conservation, environmental protection, management, and utilization projects. The need to develop innovative practices and technologies to maximize the use of what is naturally available is an ongoing challenge for NA water experts, policymakers, and the general public. Innovative researches on water in NA are proposed below:

- Getting to grips with the threats to water security is not straightforward and requires innovative and dedicated approaches. Possible responses include increasing supply, managing demand and allocating water differently;

- Seek new technologies in the areas of ground and surface water, water recycling dams, reservoirs, channels, water standards, agriculture and irrigation, coastal and port engineering, and health expertise;

- Find proper technology implementation and orientation suitable for NA;
- Development of a Water Information System Mapping for the collection of available scientific data on water resources and provide economic assessment of water supply projects and programs;

- Implementation of integrated approach to water resources management;

- Research on the environmental issues in water management and incorporation of environmental concerns into decision-making;

- Needs joint venture research for water engineering perspective, water education and public water quality awareness;

- Sharing of information is a first step toward international co-operation. A regional water network can not only serve as a repository for valuable water data and an access for computer software, but also provide a posting place for newest technology, a forum for exchange information and expertise advise;

- build an on-line information resources system to help enhance and improve communication and information sharing amongst water resources professionals in the region;

- Find new and innovative solutions to water scarcities that don't sop up the country's own energy.

\section{Sahara Solar Breeder, a new global climate policy}

The SSB plan involves building manufacturing plants around the Sahara desert that would extract silica from the sand and turn it into solar panels to generate renewable energy. The renewable energy from the first facility will then be used to breed more manufacturing plants and, in turn, more solar panels to generate ever increasing amounts of solar power. The ultimate goal is to build enough plants until the breeding strategy can deliver 100 GW of electricity to provide $50 \%$ of the world's electrical power generation capacity by 2050 which would be delivered via a global superconducting electrical grid to turn the world's biggest desert into the world's biggest power station taking advantage of two resources that are found in abundance in the Sahara namely silica and sunlight (figure 4) [12]. The development and realization of the SSB project, in the Sahara of Algeria which covers a total area of 2,048,297 $\mathrm{km} 2$, approximately $86 \%$ of the total area of the country, will tackle the key challenges and issues related to the will tackle the key challenges and issues related to the field of PV putting forward the material R/D perspective and promoting innovative processes for solar silicon with a focus on the utilization of Sahara sands. SSB is a project which proposes a plan of international partnership in basic research and development, industrial production, trade, financing... to construct, gradually over the coming decades, a "Global Clean Energy Superhighway" starting in the Sahara desert in NA (beginning from Algeria) (figure 5) [13]. SSB will help migrate from the unsustainable current excessively fossil-fuel-based global energy paradigm to a more 
sustainable one. It will also help meet global energy challenges, and mitigate climate change and other environmental problems. SSB is more than an energy solution. It is an integrated community, socio-economic, industrial, agricultural, environmental, and science and technology development solution. In particular, through desalination and adequate irrigation technologies, it will help mainstream marginal desert water resources and lands back into national, regional and international development processes. The concept of the SSB is depicted in figure $6[14,15]$.

\section{Conclusions and recommendations}

The importance of access to clean water and energy cannot be overstated. Research, Development and Demonstration (RD\&D) are the foundation for progress and change toward sustainable water and energy systems in NA region, protect the global life-supporting systems and reduce the risk of geopolitical conflicts over water and fossil fuel resources which are quickly-depleting materials. We need more electricity from Renewables, more investment and initiative to make solar energy cost effective and competitive (Sahara Solar Project, Desertec) [29]. New, less energy-intensive water cleansing techniques could revolutionize NA's desalination industry, free up important energy exports and provide residents a greater sense of water and energy security. Cooperation is crucial; problems cannot be solved by one country alone. We need to learn from each other- local, global, regional, cooperation is therefore crucial. Drivers of regional cooperation on water and energy: Geography, Resources endowment/variability, Trade, Democracy \& Governance, Power asymmetries, Diplomatic relationship, Political regimes and Colonial heritages!!!

\section{References}

[1] International Energy Agency report 2012. http://www.iea.org.

[2] Boudghene Stambouli A., Khiat Z., Flazi S. and Kitamura Y., "A review on the renewable energy development in Algeria: Current perspective, energy scenario and sustainability issues". Renewable and Sustainable Energy Reviews 16 (2012) 4445-4460.

[3] Boudghene Stambouli A., Survey report on "Renewable Energy Manufacturing Facilities in Algeria" United Nations. Index 2007; 3:382958.

[4] Allan R. Hoffman, "The Connection: Water Supply and Energy Reserves". U.S. Department of Energy (DOE), 2012. www.energy.gov.

[5] Droogers P., Immerzeel W.W., Terink W., Hoogeveen J., Bierkens, M. F. P., van Beek L. P. H., and Debele B. 2012. Water resources trends in Middle East and North Africa towards 2050, Hydrol. Earth Syst. Sci., 16, 3101-3114, doi: 10.5194/hess-16-3101-2012.
[6] Energy Engineering, "Provides resources, strategies, and information on conducting research in Energy Engineering". University of Michigan Library May 2013. http://guides.lib.umich.edu/content.php?pid=31184

[7] The Food and Agriculture Organization of the United Nations (FAO), AQUASTAT online database, "Total renewable water resources". Viewed 15th May, 2011, <http://www.fao.org/nr/water/aquastat/main/index. stm>.

[8] P. H. Gleick, "Peak water and peak energy: implications for security". Water Security, Risk \& Society, International Water Security Conference 16-18 April 2012. Univ. of Oxford, UK.

[9] M. Mason and D. Kumetat, "At the crossroads: energy futures for North Africa". Energy Policy, 39 (8) (2011). ISSN 03014215.

[10] D. Ouazar, "Middle East and North Africa Water Resources Consortium and Technology Exchange Network". EMI, MENA Secrétariat Rabat, Morocco. www.ercim.eu/medconf/papers/ouazar.html.

[11] "Middle East and North Africa Water Center Network (MENA WCN): Assessment and Design". November 2010. Publication produced for review by the United States Agency for International Development. http://menanwc.net.s79942.gridserver.com/

[12] K. Kurokawa, K. Keiichi, I. Masakazu, V. Peter Van Der, F. David, editors. "Energy from the desert- III: IEA-PVPS task-8 report". UK: James \& James Ltd.; 2009.

[13] H. Koinuma, K.Kurokawa, K.Kitazawa, H.Fujioka, M.Sumiya, Y.Furuya, K.Itaka, T.Hashimoto, S.Yamaguchi, J.Shimoyama and A Stambouli, "Oxide initiative to make the dream of "Sahara Solar Breeder Plan' come true". 17th International Workshop on Oxide Electronics, WOE-17 Abst. 100530. Awajishima, Japan

[14] A. Boudghene Stambouli and H. Koinuma, "A primary study on a long-term vision and strategy for the realisation and the development of the Sahara Solar Breeder project in Algeria". Renewable and Sustainable Energy Reviews 16 (2012) 591- 598.

[15] Sahara Solar Breeder Foundation website: http://www.ssb-foundation.com. 


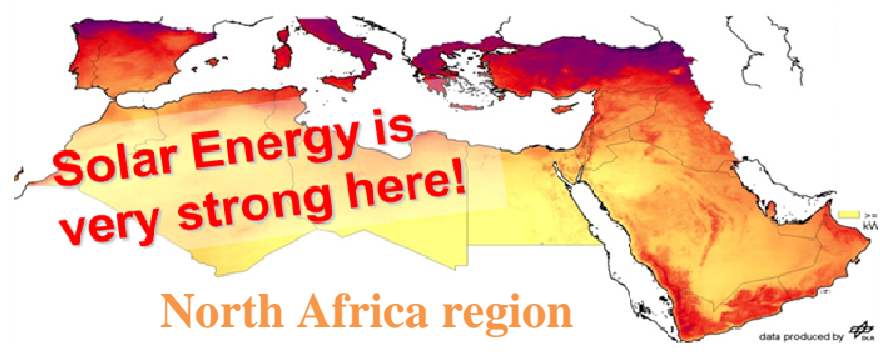

Figure 1: Potentials of solar in NA region (Economic Potential > $600000 \mathrm{TWh} / \mathrm{y}$, Maximum yield 250 $\mathrm{GWh} / \mathrm{km}^{2}$ )

Table 1: Alternative Energy and Energy intensity by country in NA

\begin{tabular}{|l|l|l|}
\hline Country & $\begin{array}{l}\text { Alternative Energy } \\
\text { (Percentage of total energy } \\
\text { use) (\%) }\end{array}$ & $\begin{array}{l}\text { Energy Intensity } \\
\mathbf{2 0 5 0}\end{array}$ \\
\hline Algeria & 0.1 & 1.87 \\
\hline Egypt & 1.9 & 3.19 \\
\hline Morocco & 0.71 & 1.11 \\
\hline Libya & 0 & No data \\
\hline Tunisia & 0.07 & 1.31 \\
\hline
\end{tabular}

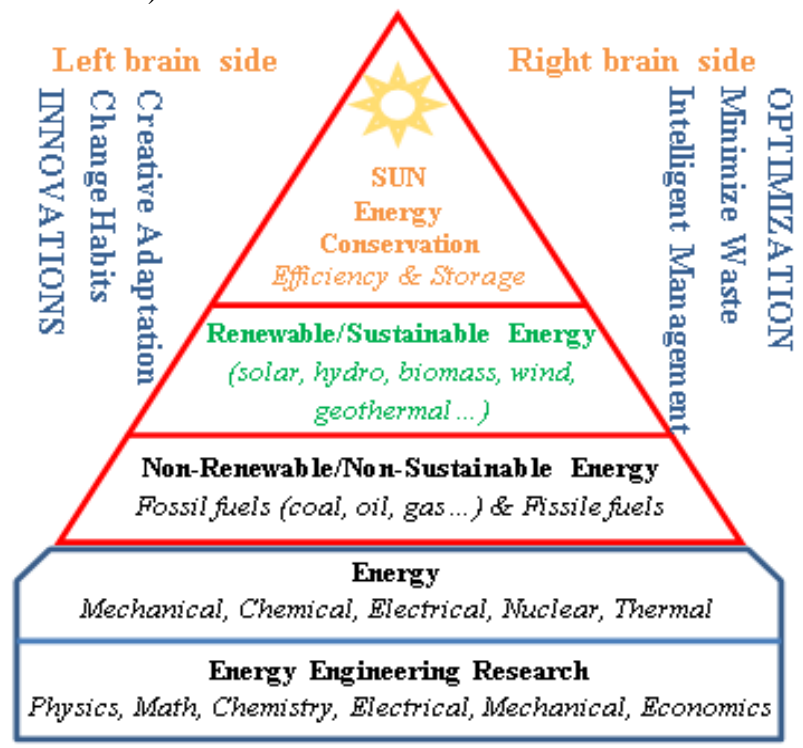

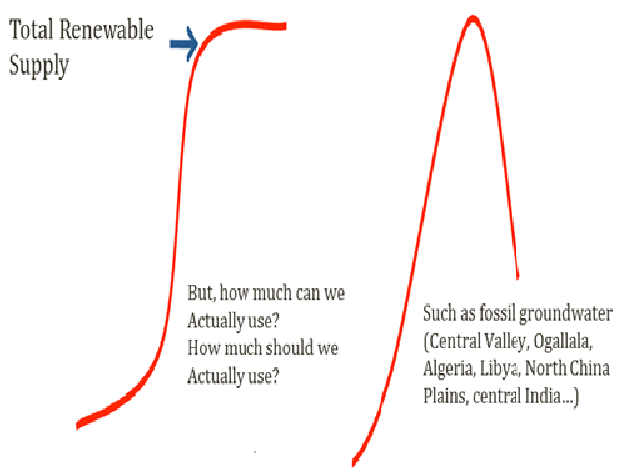

Peak Renewable Water

Peak Non Renewable Water

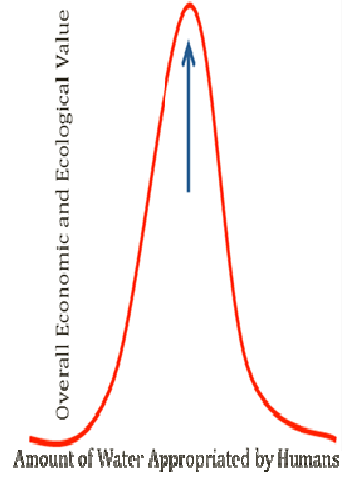

Peak Ecological Water

Figure 3: Peaks of renewable, non-renewable and ecological water

Figure 2: Energy engineering main research areas, forms of energy and energy pyramid

Table 2: Water supply and use in connection with education, health, poverty and hunger

\begin{tabular}{|c|c|}
\hline \multicolumn{2}{|r|}{ Water Supply and Use } \\
\hline $\begin{array}{l}\text { Water and } \\
\text { Education }\end{array}$ & $\begin{array}{l}\text { Education is critical for breaking the cycle of poverty } \\
\text { - } \quad \text { Lack of clean water has serious effects on student's academic performance and attendance rates } \\
\text { - } \quad \text { Lack of clean water = education simply becomes less of a priority = Lack of Equality }\end{array}$ \\
\hline Water and Health & $\begin{array}{l}\text { - } \quad \text { Potential for improving health care facilities } \\
\text { - } 1 \text { out of every } 5 \text { deaths under the age of } 5 \text { worldwide is due to a water-related disease } \\
\text { - } \quad \text { Good health begins with access to clean water } \\
\text { - } \quad \text { Poor health leads to poor productivity } \\
\text { - Clean and safe water is essential to healthy living }\end{array}$ \\
\hline Water and Poverty & $\begin{array}{l}\text { - Poverty begins with a lack of clean water and can be the result of a lack of access to clean drinking } \\
\text { water } \\
\text { - } \quad \text { Nearly } 1 \text { in } 8 \text { people on the planet do not have access to clean, safe water } \\
\text { - Without clean water, the possibility of breaking out of the cycle of poverty is incredibly slim. }\end{array}$ \\
\hline Water and Hunger & $\begin{array}{l}\text { Globally we use } 70 \% \text { of our water sources for agriculture and irrigation, and only } 10 \% \text { on domestic } \\
\text { uses. Water scarcity translates to a loss of food security } \\
\text { Water is fundamental to relieving hunger in the developing world. } 84 \% \text { of people, who don't have } \\
\text { access to improved water, also live in rural areas, where they live principally through subsistence } \\
\text { agriculture. }\end{array}$ \\
\hline
\end{tabular}

Table 3: Total renewable water resources by country in NA

\begin{tabular}{|c|c|c|c|c|c|}
\hline Country & $\begin{array}{c}\text { Renewable } \\
\text { Water } \\
\text { Resources } \\
\left(\mathbf{k m}^{\mathbf{3}} \mathbf{/ y}\right)\end{array}$ & $\begin{array}{c}\text { Renewable Water } \\
\text { Resources } \\
\text { per capita }\left(\mathbf{m}^{\mathbf{3}} \mathbf{/ y}\right)\end{array}$ & $\begin{array}{c}\text { Renewable Water } \\
\text { Resources } \\
\text { Dependency } \\
\text { Ratio }(\mathbf{\%})\end{array}$ & $\begin{array}{c}\text { Proportion of Total } \\
\text { Water } \\
\text { Resources Used }(\%)\end{array}$ & $\begin{array}{c}\text { Total Water } \\
\text { Use } \\
\text { per capita } \\
\left(\mathbf{m}^{\mathbf{3}} / \mathbf{y}\right)\end{array}$ \\
\hline Algeria & 11.67 & 339.5 & 3.6 & 52.65 & 196 \\
\hline Egypt & 57.3 & 702.8 & 96.86 & 119 & 937 \\
\hline Morocco & 29 & 917.5 & 0 & 43.41 & 427.2 \\
\hline Libya & 0.6 & 95.33 & 0 & 718 & 776.8 \\
\hline Tunisia & 4.6 & 451.9 & 8.71 & 61.74 & 296.2 \\
\hline
\end{tabular}




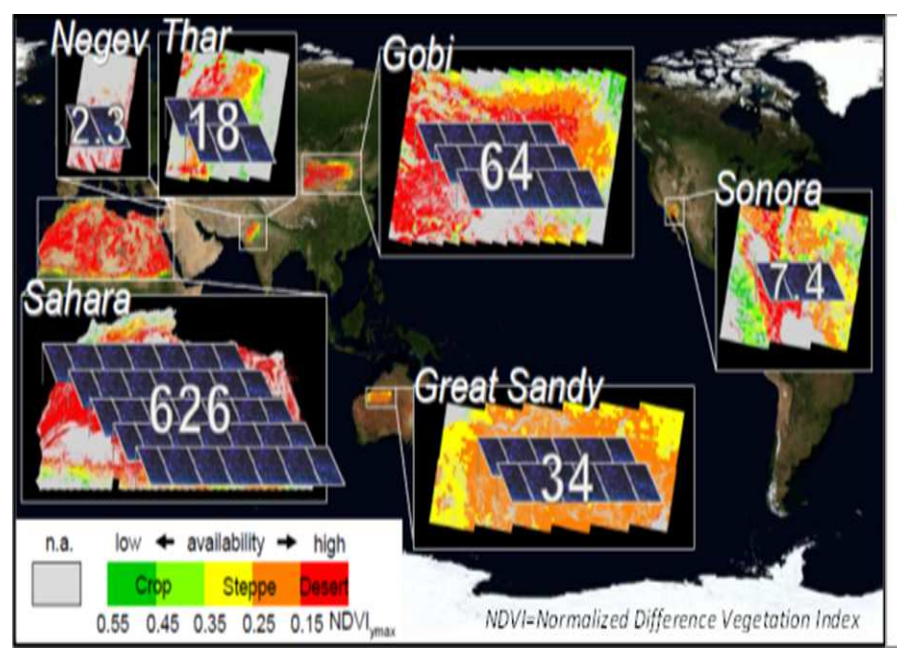

Figure 4: Solar resources of the world six deserts (TW)

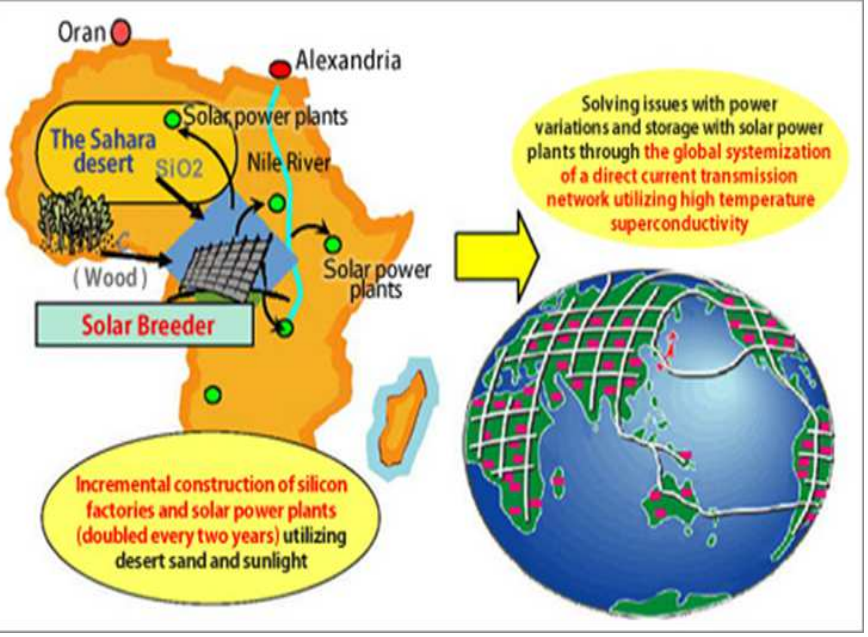

Figure 5: SSB concept and plan

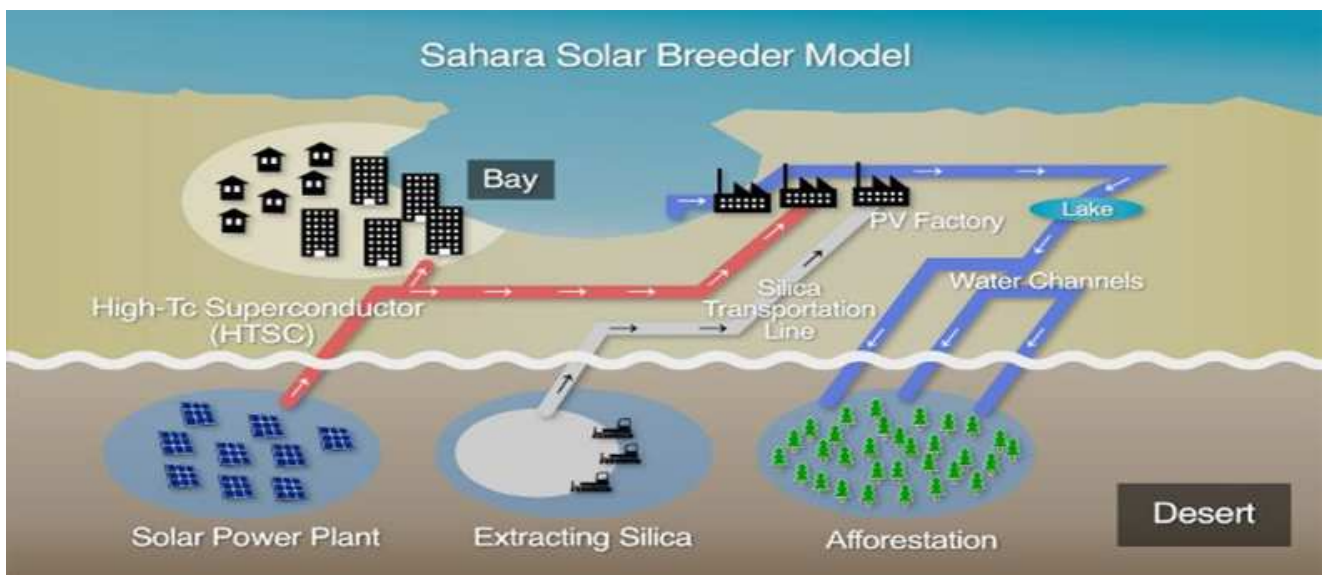

Figure 6: SSB model, key to a sustainable civilization 